\title{
Um festival é um festival Em Yerevan e no Rio de Janeiro
}

\author{
Rui Pina Coelho
}

Nestes tempos de fôlegos globais torna-se cada vez mais difícil perceber o que é um festival de teatro. A uniformização de critérios de programação e modelos de criação artística têm apressado a hegemonização de um grande número de espectáculos, sobretudo os que circulam internacionalmente apresentando-se em salas e em festivais que têm programações de perfil semelhante. Assim, o teatro (ou, pelo menos, um certo teatro), de experiência local que historicamente é, tem-se tornado cada vez mais uma experiência global, instrumento e consequência do aparentemente imparável processo de globalização mundial.

A lógica primeira deste tipo de eventos seria a de possibilitar a um espectador de um determinado local a experiência de assistir a trabalhos de diferentes estéticas, naturezas, autorias e arranjos, apresentados por criadores de diferentes partes do globo, num espaço de tempo concentrado. Simultaneamente, facilitava-se o contacto entre artistas com diferentes nacionalidades, formações artísticas, crenças e cosmovisões, potenciando cruzamentos, articulações e renovações.

A lógica comercial criará, e muito legitimamente, os festivais best-off: ou seja, aqueles que mostram espectáculos que foram sendo reconhecidos como exemplos de qualidade ou singularidade num determinado contexto, seja ele geográfico ou temporal. Reúne-se a qualidade, visando-se premiá-la e, ao mesmo tempo, criar cânones e estabelecer fasquias estéticas. Claro que também aqui a interacção entre criadores resulta em mais-valias artísticas, potenciando-se colaborações e contaminações.

Há também festivais que são epitomes de identidade cultural, numa ligação sinonímica com o local onde se desenrolam, criando autênticos fenómenos de construção identitária. São festivais que se confundem com o local que os acolhe. Estes tendem a privilegiar uma gramática especifica e a incluir na sua ideia de programação espectáculos ou manifestações artísticas que alinhem na identidade do festival. E, à medida que esta identidade se vai impondo ou ganhando reputação, começam, muito naturalmente, a aparecer espectáculos com vista a poderem ser incluidos na linha de programação privilegiada pelo festival.

Há também festivais mais singulares que se organizam em torno de um só autor, de uma só companhia, de um formato artístico, de uma tecnologia, de um género, de um tema, de uma língua, de uma região, enfim, há, como é natural, uma enorme possibilidade de modos de fazer e conceber festivais de teatro.

Esta diversidade coloca também à crítica, evidentemente, enormes desafios. Sobretudo no que diz respeito à cada vez mais frequente mobilidade e cruzamento dos espectáculos. Com efeito, há um número cada vez maior de criações que são produzidas para circuitos internacionais, ou que resultam de parcerias e co-produções com pares de várias nacionalidades, ou que envolvem várias línguas, ou que etc., etc.; por isto, se espera que também o crítico se possa mobilizar e agilizar os seus instrumentos de análise para ir ao encontro de uma realidade em permanente mutação. Este desafio é exponenciado em festivais internacionais: assim, idealmente, são ai apresentadas criações com gramáticas muito diversificadas e com recursos muito dispares a que a critica deverá saber responder adequadamente. Contudo, também acontece o contrário: precisamente porque os espectáculos habitam cada vez mais os circuitos globais, há por vezes a tentação - por parte dos criadores - de trabalhar com gramáticas universais, convidando mais facilmente espectadores e críticos de formações, estéticas e olhares diferentes, empurrando a criação para uma linguagem supostamente global.

Por todas estas razões - e por muitas outras que me escapam aqui - é cada vez mais dificil perceber o que é um festival de teatro. Neste texto, apresento dois festivais de natureza e objectivos totalmente diferentes e que tiveram lugar em duas cidades radicalmente diferentes: Yerevan, na Arménia, e Rio de Janeiro, no Brasil.

Em Yerevan, por ocasião do XXV Congresso da Associação Internacional de Críticos de Teatro, realizado em Junho de 2010, o Sindicato Arménio dos Trabalhadores de Teatro promoveu uma "mostra de espectáculos" onde se reuniram diversos grupos arménios, em variadissimas salas da cidade. A programação oferecia um leque diversificado de propostas: teatro de formas animadas, musicais, épicos, clássicos; Baudelaire, Michael Ende, Dürrenmat, Brecht, Gogol, Shakespeare, Sófocles - os mais reconheciveis pelo cânone ocidental -, mas também Saroyan, Santoyan, Teqgyozyan, Tigranyan, Yernjakyan. Se William Saroyan (1908-1981), autor norte-americano 

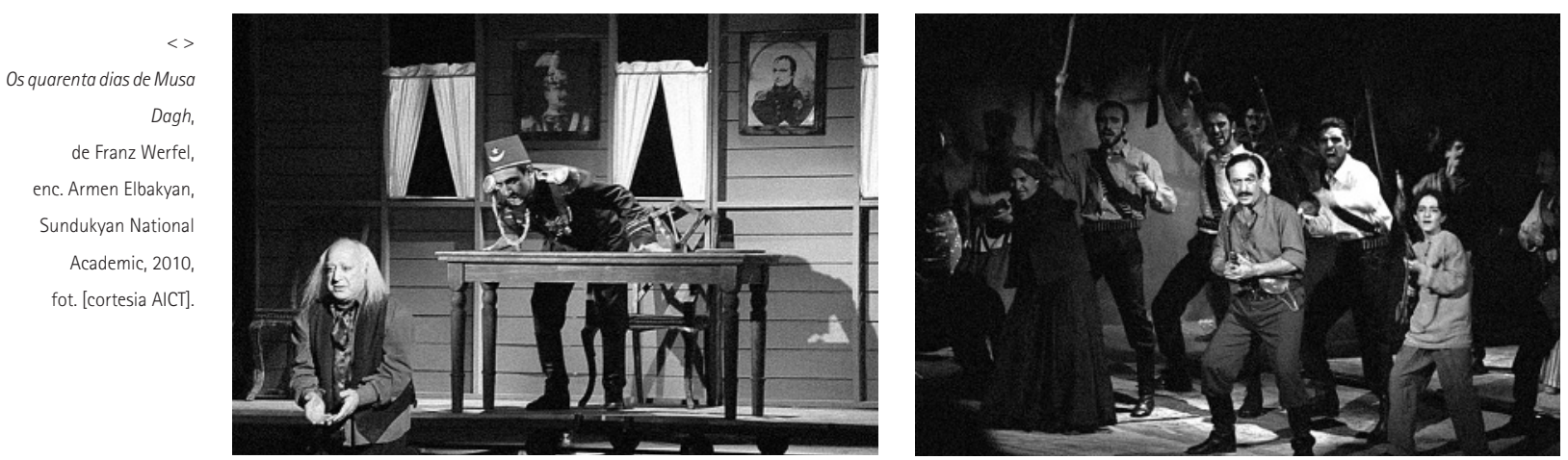
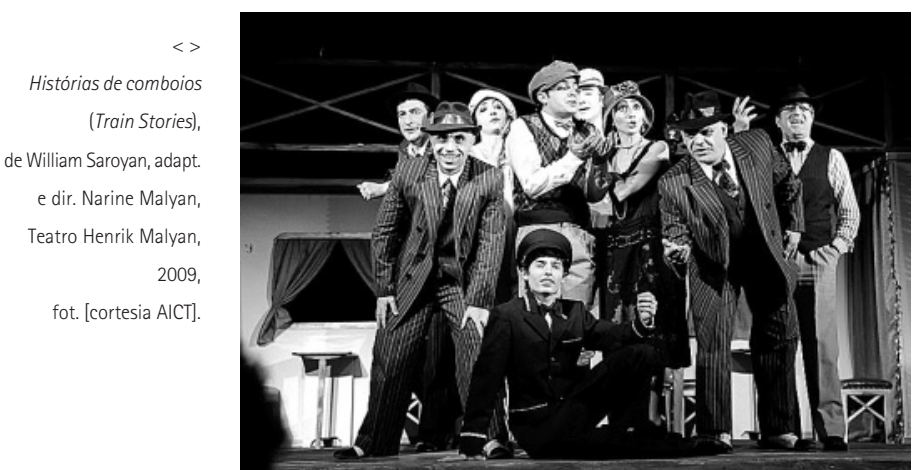

filho de emigrantes arménios, tem reputação universal, os restantes autores arménios serão menos acessíveis ao público em geral.

De entre a variedade dos espectáculos a que pudemos assistir, dois parecem dar particular conta de algumas caracteristicas aglutinadoras do teatro na República da Arménia: uma tendência para o melodrama, um forte pendor moralista, predominância dos códigos naturalistas na representação, elencos numerosos e multidisciplinares, cantando e dançando com segurança, mas também uma certa fragilidade no domínio plástico e na estética geral.

Os quarenta dias de Musa Dagh, adaptado do romance homónimo do autor austríaco Franz Werfel (obra de 1933) pelo encenador Armen Elbakyan, é baseado em factos históricos. Trata da história de resistência e fuga ao exército Turco por parte dos habitantes da aldeia de Musa Dagh, durante o Genocídio arménio perpetrado pelo governo dos Jovens Turcos, que, de 1915 a 1923, terá alegadamente eliminado 1,5 milhões de cristãos arménios, uma minoria religiosa dentro do Império Otomano, um dos episódios mais negros da história, citado frequentemente como o "Holocausto esquecido". Como, ainda hoje, a Turquia recusa assumir a existência de um genocídio orquestrado, este massacre continua a suscitar ainda enormes tensões.

Por isso mesmo, o espectáculo apresentado no Sundukyan National Academic Theatre acarretava uma excitação particular. Apresentado em registo de epopeia nacionalista, visava sobretudo engajar o público num sentimento de reconhecimento, em detrimento do possive alcance artístico. Assim, é "servido" por um vasto elenco de actores de todas as idades, em registo declamatório e exagerado, num cenário bidimensional, com interiores decorados por um pretenso realismo, salpicado com alguns elementos simbólicos (tais como pedaços de linhas ferroviárias que saem das laterais). Os quadros em que se vai narrando a luta de Gabriel Bagradian - um sargento de artilharia do exército Otomano, distinguido por heroismo

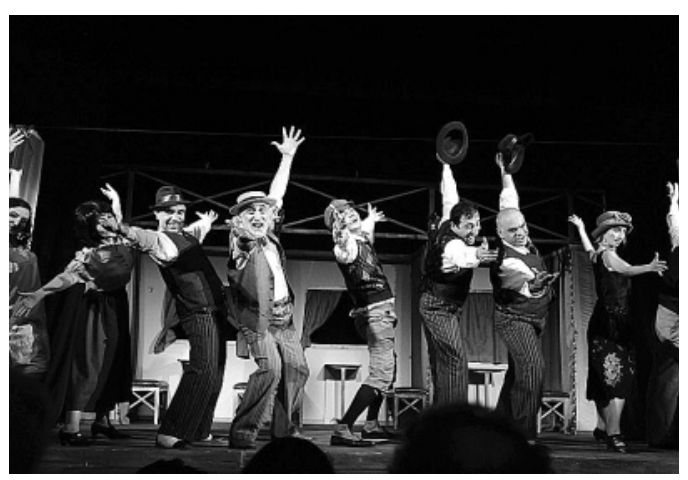

na guerra dos Balcãs de 1912 - e da sua família, que se vêem obrigada a fugir às tropas turcas, exilar-se nas montanhas e ajudar vizinhos e amigos a escapar ao avanço turco, vão-se sucedendo, numa lógica de crescente tensão, interrompida - por parte de um público cúmplice - por frequentes explosões de aplausos e ruidosas manifestações de desagrado para com as acções das personagens do exército turco. Tal empatia entre cena e plateia revelavase sobretudo nas canções, acompanhadas em coro emocionado pelo público. Não adiantará acrescentar que os agradecimentos foram um momento de explosão de regozijo e catarse e que os actores que interpretavam as vis personagens turcas não podiam aparecer mais envergonhados. Em suma, um espectáculo que desarma qualquer aproximação distanciada.

Tal não é o caso de Histórias de comboios (Train Stories) de William Saroyan, adaptado e dirigido por Narine Malyan apresentado pelo Teatro Henrik Malyan, estreado em 2009 tendo recebido o importante prémio para o teatro arménio Artavaz (espectáculo do ano, melhor actriz e melhor actor secundário) e, em 2010, o prémio anual da Fundação Cultural Tekeyan, para a categoria de teatro. Este espectáculo é construido a partir de seis contos de Saroyan: "O barbeiro a cujo tio foi arrancada a cabeça por um tigre do circo", "Velhas instruções provincianas para um americano em viagem", "O génio", "Bitlis", "Os jogadores de ping-pong" e "História do árabe pobre e ardente". Assim, o alinhamento dramatúrgico dá conta da história do jovem Aram, que antes de embarcar numa viagem de comboio pela primeira vez na vida, é aconselhado pelo seu avô a nunca acreditar no guarda da estação, a nunca aceitar um cigarro de um desconhecido, a manter-se afastado das mulheres insinuantes e a nunca jogar cartas com três estranhos. Claro que o jovem vai falhar todas as promessas envolvendo-se numa série de pitorescas aventuras. Contudo, o tom moralista prevalecerá, sabendo o jovem preservar os costumes transmitidos pelo seu avô, os da 


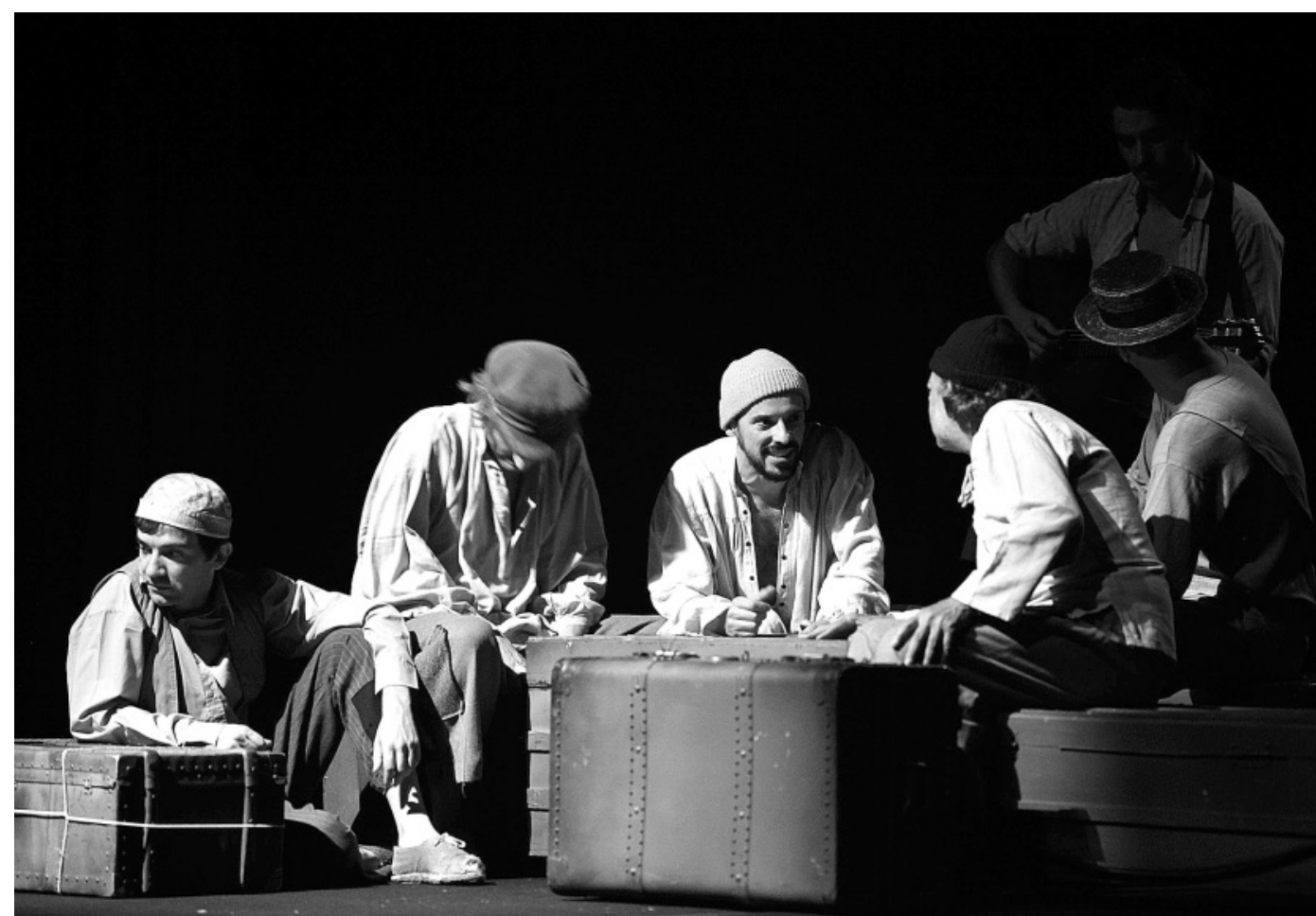

ruralidade, dos bons hábitos e os da simplicidade, rejeitando a corrupção que o mundo exterior insinua. Jogado com pulsão fársica, em registo de filme mudo, com predomínio de humor físico e com personagens traçadas a grosso caricatural (os guardas, os gangsters, as raparigas, os passageiros...) o espectáculo, embora plasticamente muito deficiente, compensava em entrega, ritmo e energia por parte dos actores, sendo, a espaços, bastante contagiante.

Ambos os espectáculos parecem saber devolver ao público um retrato razoável dos valores dominantes, embrulhados num tom declaradamente moralista. Isto, como é óbvio, retira poder de confronto e desafio, mas ganha em capacidade de identificação. A história do jovem Aram é tratada como uma fábula de aprendizagem onde se reforçam os valores da comunidade e da preservação dos laços identitários. Porém, o tratamento do genocídio em Os quarenta dias de Musa Dagh levanta algumas questões suplementares: a linearidade com que se aborda o tema e, sobretudo, o convite à galvanização das paixões envolvidas está perigosamente perto de estratégias populistas que aportam muito pouco à discussão.

Numa outra ponta do globo, no Rio de Janeiro, de 14 a 25 de Julho de 2010, teve lugar a terceira edição de um festival de contornos absolutamente diferentes: o FESTLIP, Festival de Teatro da Língua Portuguesa, organizado pela Talu Produções, com - pela primeira vez - espectáculos de colectivos oriundos dos oito países da CPLP (Comunidade dos Países de Língua Portuguesa), Angola, Brasil, Cabo Verde, Guiné-Bissau, Moçambique, Portugal, S. Tomé e Príncipe e Timor-Leste. Nas palavras de Tânia Pires, a directora geral e artistica deste Festival, onde a especificidade de cada contexto cultural é tratada com singularidade, todos os participantes são "[f]ilhos de uma mesma língua, que sabem que a troca é essencial para a unificação destas culturas, sem que esta violente as características próprias de um só povo" (programa da $3^{\circ}$ edição do FESTLIP).
Depois de na primeira edição (2008) Portugal ter sido representado pelo Teatro da Garagem (A hora do arco-íris) e pelo Teatro o Bando (Luto clandestino), e na segunda (2009), pelos Artistas Unidos (Uma solidão demasiado ruidosa) e Primeiros Sintomas (Lindos dias), em 2010, numa edição que homenageava Maria do Céu Guerra, os representantes portugueses foram A Barraca (Agosto: Contos da emigração, dir. Maria do Céu Guerra), o Teatro Meridional (Contos em Viagem: Cabo Verde, enc. Miguel Seabra - espectáculo revelação), Trigo Limpo (Chovem amores na rua do matador, dir. Pompeu José) e Binólogos (Filhas da mãe: Fantasias eróticas das mulheres portuguesas, dir. Célia Ramos e Catarina Ascensão). De resto apresentavam-se os seguintes grupos e espectáculos: de Moçambique, a companhia de Teatro Gungu (A demissão do sô ministro, de Gilberto Mendes) e a Companhia de Teatro Kudumba (Só cheira a borracha, de Cândida Bila); de Angola, a Companhia de Teatro Dadaísmo (Olímias, de Hilário Nelson) e Miragens Teatro (4'30", de Cris Wall de Sá, enc. Walter Cristóvão); da Guiné-Bissau, o Grupo Teatro do Oprimido (Maria, ritual das parideiras, de Bárbara Santos e Alessandra Vanucci); do Brasil, Os Fofos Encenam (Ferro em Brasa, de António Sampaio, enc. Fernando Neves), Cia Novo Ato (Drummond 4 Tempos, de Luiz Cláudio) e Barracão Cultural (A mulher que ri, de Paulo Santoro, enc. Yara de Novaes); de Cabo Verde, o Centro Cultural de Mindelo (Androginia, de Caplan Neves); de Timor-Leste, o Grupo Arte Lorosae (Saramau, de Carolina Pereira Rodrigues e Milena da Silva, enc. Waldo Luna e Milena da Silva); e de São Tomé, o Grupo Fôlô Blagi (O pagador de promessas, dir. Izabela Brochado).

0 nivel artístico dos diversos grupos e espectáculos que integravam esta oferta era muito dispar. Desde colectivos com clara dimensão amadora até aqueles com certificada rotina de trabalho e com perfil internacional, a programação foi de uma grande variedade. Mas a verdade é que esta é uma das mais estruturantes características 


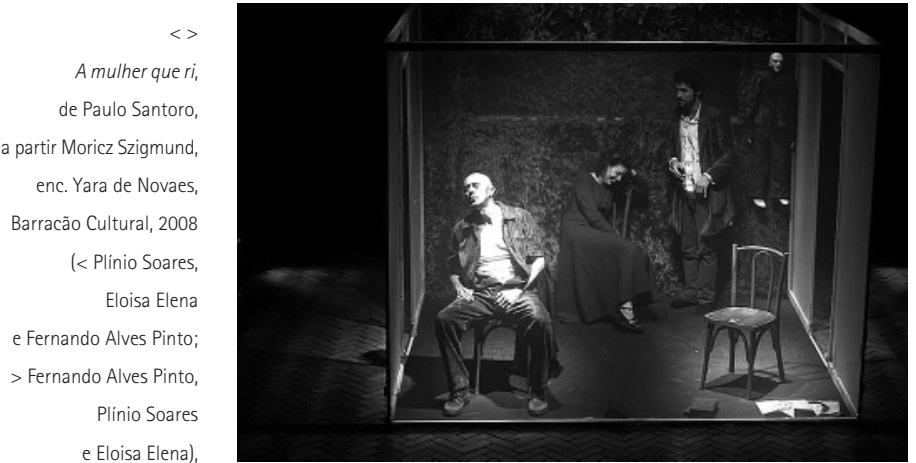

deste festival. Há a vontade de criar uma comunidade artística em torno do Festival, promovendo aprendizagens e apressando processos de aquisição de competências pelo contacto com outros artistas mais experientes ou com metodologias diferentes. Com efeito, a programação compreende também oficinas técnicas e artísticas, bem como debates e, entre cada edição, a produção promove encontros e ateliês nos diferentes paises envolvidos. Assim, havendo um núcleo de participantes que tem repetido a presença no festival, cria-se uma comunidade mais ou menos estável que vai garantindo a identidade do evento e, mais importante, que vai crescendo artisticamente com a participação no FESTLIP. Para Christina McMahon, que tem acompanhado o teatro na lusofonia, este festival é "um espaço onde artistas de três continentes podem perscrutar os mitos residuais e os enganos em torno da sua história de colonialismo, que ainda os une" (McMahon 2010: 285)

Um dos destaques desta edição foi o espectáculo d'A Barraca, Agosto: Contos da emigração. Sendo já um trabalho de 2007 onde se revisitava o espectáculo Agosto: histórias de emigração, de 1999, é dirigido por Maria do Céu Guerra a partir de textos de Ferreira de Castro, José Rodrigues Miguéis, Dias de Melo, João de Melo, Manuela Degerine e Olga Gonçalves. Trata da diáspora da emigração portuguesa dando conta de muitos dos seus destinos e razões: das Beiras, do Alentejo, dos Açores; para a América, para o Brasil, para França; mas sempre procurando a vida que não parecia possivel por cá. Num tom assumidamente épico, em registo rapsódico, sucedem-se os pequenos quadros onde se retratam as partidas e as pequenas epopeias dos emigrantes. Num registo polvilhado com humor, mimam-se sotaques, costumes e cantigas. Com efeito, será mesmo a música que vai assegurando o refrão do espectáculo, com interpretações seguras e vibrantes de um reportório luso-afro-brasileiro.

Mas a pedra de toque deste espectáculo será a maneira como toda a cenografia é construída pela inventiva utilização de várias malas. Assim, carrinhas, muros, paredes, mesas, comboios, tudo é construído pela composição e junção de malas, o que, além de sinalizar as míticas "malas de cartão" da emigração portuguesa, dá a todo o espectáculo uma dinâmica extraordinária. Ainda que Agosto ganhasse ritmo e energia se se tivesse optado pela simultaneidade de acções (ao contrário da referida sucessão de quadros), esta é uma obra de apurada criação, na melhor tradição dos primeiros tempos d'A Barraca: popular, inventiva e interventiva.

A mulher que ri, do colectivo Barracão Cultura, de São Paulo, pela delicadeza e finura, terá sido outro dos momentos altos da programação do festival. Trata-se de

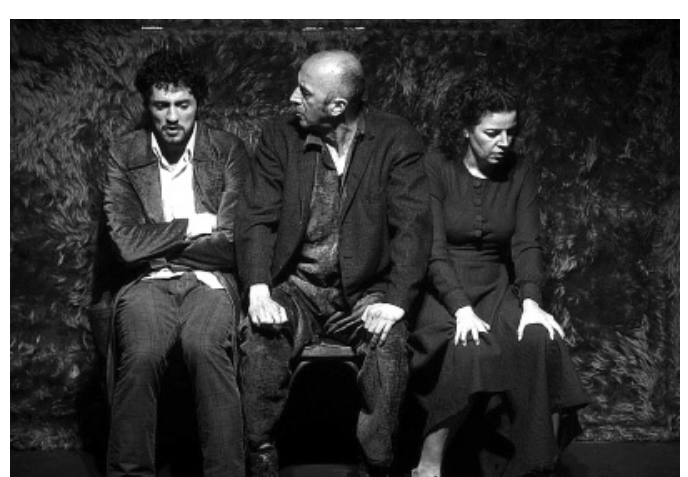

uma adaptação do conto "Sete Krajcár", do autor húngaro Moricz Szigmund (1879-1942), da responsabilidade de Paulo Santoro, e encenado por Yara de Novaes. Misturando narração e diálogo, o espectáculo trata da história de reconciliação de um escritor com o seu passado e com os seus pais, alicerçado numa dramaturgia declaradamente poética. Munido de um caderno de notas e com problemas de memória, um escritor tenta reconstruir os passos que o levaram à escrita. Para além da vida familiar, contamse as lutas operárias, as greves, o conflito com um pai que desconfiava do comunismo, a luta pela sobrevivência de uma familia proletária que investia no futuro do filho todas as esperanças de vida melhor. 0 pai, crucificado pelo trabalho, ia desistindo. Mas a mãe, ia rindo, mudando para sempre a maneira de o seu filho ver o mundo, empurrandoo para a escrita e para a procura de felicidade, mas afastando-o de casa. Com três interpretações deliciosas, rigorosas e tremendamente emotivas (de Eloisa Elena, Fernando Alves Pinto e Plínio Soares), o espectáculo decorria essencialmente dentro de uma caixa alcatifada (a casa da familia), em tons vermelhos, quentes e seguros. Ao redor da casa, um largo quadrado de madeira, como se de um piso de tacos se tratasse, trazia para o exterior o lado de dentro da casa, revelando ao público este drama familiar Tudo arquitectado com saber e ternura: em suma, um espectáculo de grande sensibilidade e rigor.

Estes dois eventos - a mostra de espectáculos em Yerevan e o FESTLIP no Rio de Janeiro - pela sua natureza singular ajudam a perceber a diversidade de modos de pensar os festivais. Contudo, ambos são exemplos de festivais que se constituem como fenómenos locais, radicando a sua existência na sua circunstância geográfica. Patrice Pavis vê o "moderno ressurgimento do festival sagrado" como resposta a "uma profunda necessidade de um momento e de um lugar onde um público de 'celebrantes' se encontre periodicamente para tomar a pulsação da vida teatral (...) e, mais profundamente, ter a sensação de pertencer a uma comunidade intelectual e espiritual encontrando uma forma moderna de culto e ritual" (Pavis 1999: 166). Talvez seja este o papel que estas celebrações periódicas reservam ao espectador moderno: reforçar os laços identitários de uma comunidade.

\section{Referências bibliográficas}

McMAHON, Christina S. (2010), "Festlip 2009" (Review), Theatre Journal, Volume 62, Number 2, May, pp. 280-285.

PAVIS, Patrice (1999), Dicionário de Teatro, trad. J. Guinsbourg \& Maria Lúcia Pereira, S. Paulo, Editora Perspectiva. 